3 Altmann, F, in Otosclerosis: Henry Ford Hospital International Symposium, ed H F Schuknecht. London, Churchill, 1962.

${ }^{4}$ Morrison, A W, Annals of the Royal College of Surgeons, 1967, 41, 202.

5 Wright, I, Fournal of Pathology, 1977, 123, 5.

${ }^{6}$ Sercer, A, and Krmpotic, J, fournal of Laryngology and Otology, 1958, 72, 688.

7 Causse, J, et al, Clinical Otolaryngology, 1977, 2, 23

${ }^{8}$ Miot, C, Revue Laryngologie (Bordeaux), 1890, 10, 113, 145, 200.

${ }^{9}$ Jack, F L, Transactions of the American Otological Society, 1891-1893, 5, $284,474$.

${ }^{10} \mathrm{Kessel}, \mathrm{J}$, Über di vordere Tenotomie Mobilisirung und Extraction des Steigbügels. Jena, Fischer, 1894.

11 Lempert, J, Archives of Otolaryngology, 1938, 28, 42.

12 Dawes, J D K, and Curry, A R, fournal of Laryngology and Otology, 1969, 83, 641 .

13 Dawes, J D K, and Curry, A R, fournal of Laryngology and Otology, 1974, 88, 213.

\section{Describing new syndromes}

The classification and study of developmental abnormalities start with identifying disease entities. This often relies on the definition of a composite picture from several variables including the clinical appearances, aetiology, pathogenesis, treatment, and prognosis of a sample of those affected. This method is and has been very useful-with the caveat that it should be applied cautiously to prognosis, which in developmental disease may lead to a self-fulfilling prophecy.

Recently Garlinger et $a l^{1}$ have used this approach to try to distinguish between a complete and a partial trisomy in Down's syndrome and so to identify a recognisable new clinical entity, partial trisomy 22 . They relied on one case of their own and 16 derived from published reports. The children ranged in age from newborns to 17 years. The delineation of a new clinical entity in this context requires attention to continuous variables such as IQ, linear growth, craniofacial asymmetry, the interorbital space, the slant of orbital fissures, length of philtrum, the siting and configuration of external ears, and the size of mandible. The authors state, "The facial features of our case 1 show a striking resemblance to those of other translocation cases-mild coarseness of features with a broad nose and a long philtrum." These features are difficult to measure and in the absence of objective methods photographs are invaluable to capture the clinical observer's concept. The photographs published in support of the new syndrome are far from convincing, however, and the other publications cited refer to children of widely different ages and states of nutrition, which again makes comparison very difficult. Furthermore, Garlinger et al clustered together major system abnormalities to imply a commonality of aetiology that can be misleading. Thus they advance diverse skeletal variations such as scoliosis, hypoplasia of the middle phalanx, and overgrowth of the medial femoral condyle as constant variables occurring in the partial trisomy. They emphasise, and correctly so, the difficulty in identifying a single small acrocentric chromosome; and yet they categorise two cases $^{2} 3$ as examples of partial trisomy though this disagrees with the original authors' interpretation. In such circumstances they should surely have justified their own assessment.

What, we may ask, is the justification of such criticism of a single article in a specialist journal? There are two general principles at issue. Firstly, labelling as a result of categorisation may create real problems for the individuals so affected. Garlinger et al designated as mentally retarded 14 of the 17 children described, though six were aged less than $2 \frac{1}{2}$ years and three others under 4 months. Mental retardation is a pejorative term to many professionals and families, and, though patients with autosomal chromosome abnormalities are at high risk for developmental delay and ultimately mental retardation, it serves no good purpose to lump them all together. Labelling in this manner is all too frequent in medical publications and has contributed to the number of children who function at the retarded level because they are expected to do so.

Secondly, professional meetings and gatherings are replete with accounts of new syndromes based on anecdotal information about unusual or flawed children. These reports generally lack evidence based on clinical measurement using techniques and values of the kind compiled by David Smith, ${ }^{4}$ William Nyhan, ${ }^{5}$ and others. In the absence of such objective data high quality clinical photographs are absolute requirements. Investigators and editors should be as critical in their publication of clinical data and photographs as they are of laboratory values.

${ }^{1}$ Garlinger, P, McGeary, S A, and Magenis, E, Clinical Genetics, 1977, $12,9$.

Zackai, E, et al, American fournal of Human Genetics, 1973, 25, 89A.

${ }^{3}$ Emanuel, B S, et al, fournal of Medical Genetics, 1976, 13, 501.

Smith, D W, Major Problems in Pediatrics VII. Philadelphia, Saunders, 1970

${ }^{5}$ Nyhan, W L, and Sakati, N O, Genetic and Malformation Syndromes in Clinical Medicine. Chicago, Year Book Medical Publishers, 1976.

\section{Pemphigoid}

Of the many questions about pemphigoid that remain to be answered, two are of current interest. The first concerns the relation between the three syndromes in the adult to which the term pemphigoid is applied. The second is the pathogenic significance of the autoantibodies in pemphigoid.

The term pemphigoid was coined in France during the nineteenth century, probably by Besnier, and applied by him and by Colcott Fox in London to a bullous eruption, which should be differentiated from pemphigus. ${ }^{1}$ The diagnostic criteria, however, were clinical and differed from country to country in accordance with strikingly divergent concepts and classifications of the bullous diseases. The systematic histological study of these diseases was undertaken by A Civatte of Paris, but as the second world war was in progress his findings were at first little known outside France. After the war they were continued and extended by investigators in many countries. Lever in Boston had independently differentiated what he called bullous pemphigoid from pemphigus, also on histological grounds. Subsequent histological refinements confirmed the further differentiation, usually clinically obvious, of pemphigoid from dermatitis herpetiformis. The discovery of the latter's association with jejunal abnormalities was followed by a report of the absence of these in pemphigoid. ${ }^{2}$

A new dimension was then added to the study of bullous diseases by developments in immunopathology, and in particular by immunofluorescence techniques. The histological distinction between pemphigus and pemphigoid was reinforced by the finding ${ }^{3-5}$ of circulating autoantibodies to different zones of the skin. Immunofluorescence is seen in the intercellular spaces in pemphigus while in pemphigoid it occurs at the basement membrane zone. In dermatitis herpetiformis the diagnostic feature is the presence of granular deposits, consisting largely of $\operatorname{IgA}$, at the tips of the dermal papillae. 
Of the three clinical forms of pemphigoid in adult life, bullous pemphigoid-the term is clumsy, but it is widely accepted-presents as, or rapidly becomes, a generalised or extensive eruption of tense bullae. It may run a prolonged course but ultimately remits spontaneously in about half the cases $^{6}$ and leaves no scars. Lesions develop in the oral mucosa in $25^{\circ}{ }_{0}^{6}$ to $45 \%$ of cases; these are usually slight. Immunoglobulins, mainly IgG, and complement are found in the basement membrane zone in all cases, and circulating antibodies are present in $70^{\circ}{ }_{0}{ }^{6}$

Cicatricial pemphigoid, formerly known as ocular pemphigus, affects the oral, ocular, or genital mucous membranes in all cases and the skin in $30^{\circ}{ }_{0}$; here there is no tendency to permanent spontaneous remission, and recurrent attacks in the same sites cause scarring. In most cases immunoglobulins, both IgG and IgA, and complement are present in the basement membrane zone, but circulating antibodies are rarely detectable.

In localised chronic pemphigoid bulla formation, with scarring, is confined for many years to a more or less circumscribed region of the face, scalp, trunk, or limbs without affecting the mucous membranes. Too few cases have been adequately investigated to point to any firm conclusions; but again both IgG and complement seem to be present in the basement membrane zone (circulating antibodies have not been detected).

Clearly the three adult forms of pemphigoid have much in common. Whether immunological factors underlie their differences, which are helpful for treatment and prognosis, is uncertain. An individual's immunological status can change rapidly; and antigen-antibody complexes may be removed by phagocytic inflammatory cells. One case of localised chronic pemphigoid, recently reported, ${ }^{6}$ shows the danger of classifying cases on the basis of the immunological findings in a single biopsy. In three and a half years five biopsies were taken from the lesions. The first showed no specific immunofluorescence; the second and third biopsies showed weak linear staining, and the fourth and fifth showed strong linear staining in the basement membrane zone. In the fourth biopsy IgG and the C3 fraction of complement were detected, and in the fifth $\operatorname{IgM}$ as well.

Ahmed, Maize, and Provost ${ }^{8}$ studied the effect of treatment on the clinical and immunological status of 36 patients with pemphigoid, localised in seven and generalised in 29. The direct immunofluorescence staining of the initial biopsies showed C3 in all 36 and $\operatorname{IgG}$ in 32 ; while $\operatorname{IgM}, \operatorname{IgE}, \operatorname{IgA}$, and IgD were each detected in from 4 to 12 cases. No correlation was found between any specific immunoglobin and the presence of extensive disease. Twenty-five of the patients had circulating antibodies to the basement membrane zone, but the titre was not related to the extent or activity of the disease. The seven patients with localised pemphigoid were treated with topical corticosteroids. Of the patients with generalised disease 14 were treated with prednisone alone and 15 with azathioprine and prednisone. Treatment was continued until there was both a clinical remission and disappearance of the immunological evidence of disease. Sixteen patients completed treatment and remained clinically and immunologically normal. Six were still receiving treatment but were also immunologically normal. Five still under treatment were clinically clear but had IgG in the basement membrane zone though no circulating antibodies, while three others who were clinically free from disease showed no abnormal immunofluorescence in skin biopsies but still had circulating antibodies. Despite the many immunological inconsistencies in their findings Ahmed et al argued that the consistent occurrence of IgG or C3 at the site of the pathological disturbance in the region of the basement membrane suggests they are important in bulla formation.

1 Macleod, J M H, British Fournal of Dermatology, 1915, 27, 201

2 Marks, J, and Shuster, S, Archives of Dermatology, 1969, 100, 136.

${ }^{3}$ Christophers, E, and Braun-Falco, O, Hautarzt, 1967, 18, 212.

4 Cormane, R H, and Szabò, E, British fournal of Dermatology, 1970, 83, 435.

${ }^{5}$ Chorzelski, T P, et al, in Immunopathology of the Skin: Labelled Antibody Studies, eds E H Beutner et al, p 25. Stroudsburg, Pennsylvania, Dowden, Hutchinson and Ross, 1974.

${ }^{6}$ Nieboer, C, Roeleveld, C G, and Kalsbeek, G O, Dermatologica, 1978, 156, 24.

Shklar, G, Meyer, I, and Zacarian, S A, Archives of Dermatology, 1969, 99, 663.

${ }^{8}$ Ahmed, A R, Maize, J C, and Provost, T T, Archives of Dermatology, 1977, 113, 1043.

\section{Promissory note?}

The BMA's demand last July for an interim pay review ${ }^{1}$ was taken against a background of widespread expectation that phase 3 of the Government's incomes policy could well crumble quickly. But Downing Street's subsequent dogged defence not only of the 12-month rule (overtly supported by the TUC) but also of the $10 \%$ limit (covertly supported by the TUC) has so far prevented any pay explosion. So the moderate tone of the evidence from the BMA and the BDA (p 125), submitted last November, has been shown to be tactically wise. They acknowledged the 12-month rule but spelt out the two professions' rapidly deteriorating position in the national incomes' league. In addition, they emphasised the incompatibility of this pay policy with the principles of professional remuneration (by detailing the serious anomalies that have developed in doctors' pay) and deplored the handicap facing the professions in trying to use the one element of flexibility in the $10 \%$ restraint-namely, self-financing productivity deals.

The Review Body's Seventh Report strongly supported the profession's case, though the award itself was within the official guidelines. ${ }^{2}$ Sir Ernest Woodroofe's letter to the Prime Minister about the interim review (p 124) comes down even more strongly on the professions' side. As a declaration of intent doctors could not have asked for much more. But a promise by the Review Body is a long way from cash in the bank. The Secretary of State's recent pronouncements on the consultant contract negotiations ${ }^{3}$ and loud hints by senior ministers about even stricter pay guidelines in 1979 will make doctors wonder whether their comparative living standards will ever be restored, however vigorously the Review Body declaims the merits of their case. Indeed, the Review Body's figure of $15^{\circ}$, for the "overall average shortfall" since April 1975 in the income of doctors and dentists as a group as compared with other professional groups hides some wide differences. Furthermore, if the juniors' UMT payments are excluded (on the grounds that few of the comparable earnings in the April 1977 survey quoted by the Review Body chairman include significant amounts of overtime) the average figure could well be around $20^{\circ}$. It will need some politically unpalatable increases to undo this damage.

The Government has already made some substantial promises to the police and the firemen-though it is of interest that a future Conservative administration would not feel bound, apparently, to support any commitment to the latter ${ }^{4}$ and the 